\title{
Reply to the letter regarding double-C hold for bag-mask ventilation during resuscitation
}

\author{
Tomoyuki Saito $^{1} \cdot$ Takashi Asai $^{1}$
}

Received: 9 November 2021 / Accepted: 10 November 2021 / Published online: 14 November 2021

(c) The Author(s) under exclusive licence to Japanese Society of Anesthesiologists 2021

\section{To the Editor:}

We thank Dr. Isser and colleagues for their constructive comments [1] to our report which has indicated a potential use of a transportable compact high-flow extractor in minimizing the risk of infection to healthcare worker during airway management, in patients with and without diagnosis of COVID-19 [2].

In their letter, Dr. Isser and colleagues have suggested two additional protective measures during cardiopulmonary resuscitation: the double-C hold for bag-mask ventilation, and blanketing the patient with a plastic barrier [1]. We agree with Dr. Isser and colleagues that an air-tight seal would be required during bag-mask ventilation to reduce the risk of aerosol contamination. Please note though that "Consensus guidelines for managing the airway in patients with COVID-19" [3] recommend the two-handed two-person bag-mask technique with the VE hand position, and state that the $\mathrm{C}$ hand position should be avoided.

We also agree that a thin plastic barrier may reduce the risk of contamination by vomit, blood, and body fluids. Nevertheless, we should judge whether it is justifiable to use such a barrier, because any "aerosol containment device" would make airway management more difficult, and because such a device without vacuum mechanism may increase, rather than decrease, the risk of healthcare workers being exposed to a higher concentration of viral aerosols $[4,5]$. In addition, placing a plastic barrier over the patient's face may not be suitable, when the patient is breathing spontaneously, actively coughing or vomiting.

This reply refers to the comment available online at https://doi.org/ 10.1007/s00540-021-02935-7.

Tomoyuki Saito

s-tomo@dokkyomed.ac.jp

1 Department of Anesthesia, Dokkyo Medical University

Saitama Medical Center, 2-1-50 Minami-Koshigaya,

Koshigaya, Saitama 343-8555, Japan
We believe that a transportable compact high-flow extractor is useful to minimize the risk of infection to healthcare worker during airway management, not only in patients who require resuscitation, but also in those who are breathing spontaneously.

Funding None.

\section{Declarations}

Conflict of interest The authors declare that they have no conflicts of interest.

\section{References}

1. Isser M, Salchner H, Lederer W. Double-C hold for bag-mask ventilation during resuscitation. J Anesth. 2021. https://doi.org/ 10.1007/s00540-021-02935-7.

2. Saito T, Fujishiro A, Asai T. Aerosol extractor for airway management of COVID-19 patients. J Anesth. 2021;35:323.

3. Cook TM, El-Boghdadly K, McGuire B, McNarry AF, Patel A, Higgs A. Consensus guidelines for managing the airway in patients with COVID-19: Guidelines from the Difficult Airway Society, the Association of Anaesthetists the Intensive Care Society, the Faculty of Intensive Care Medicine and the Royal College of Anaesthetists. Anaesthesia. 2020;75:785-99.

4. Saito T, Taguchi A, Asai T. Videolaryngoscopy for tracheal intubation in patients with COVID-19. Br J Anaesth. 2020;125:e284-6.

5. Saito T, Asai T. Aerosol containment device for airway management of patients with COVID-19: narrative review. J Anesth. 2021;35:384-9.

Publisher's Note Springer Nature remains neutral with regard to jurisdictional claims in published maps and institutional affiliations. 